\section{Therapeutischer Quotient}

C. Vidal ${ }^{1}$ und W.-R. Külpmann ${ }^{2}$

${ }^{1}$ Landeskriminalamt Niedersachsen, Dezernat 53 „Chemie“, Hannover, Deutschland

${ }^{2}$ Hannover, Deutschland

Englischer Begriff therapeutic ratio

Definition $L D_{50} / E D_{50}$

$E D_{50}$ : Dosis, die bei $50 \%$ der Probanden die erwünschte Wirkung hervorruft.
$L D_{50}$ : Dosis, die $50 \%$ der Organismen tötet.

Beschreibung Der therapeutische Quotient soll ein $\mathrm{Ma} ß$ sein für die potenzielle Gefährdung bei Applikation eines Pharmakons, das jedoch leicht zu Fehlschlüssen verleitet.

\section{Literatur}

Wellhöner HH (1997) Pharmakologie und Toxikologie, 6. Aufl. Springer, Berlin/Heidelberg/New York 